\title{
The simulation of volume shrinkage for double-injection molding with PC and ABS
}

\author{
Pichai Leklong ${ }^{1}$ and Wipoo sriseubsai ${ }^{1, *}$ \\ ${ }^{1}$ Industrial Engineering Department, Faculty of Engineering, King Mongkut's Institute of Technology Ladkrabang, Bangkok, Thailand.
}

\begin{abstract}
The objective of this paper was to study and analyze the plastic injection molding parameters to reduce the volume shrinkage of double injection molded part. The specimen was molded with Acrylonitrilebutadiene-styrene (ABS) after Polycarbonate was molded as a half part. The weld line occurred at the haft of the molded part. The simulation with Moldex 3D R13 and the design of experiment with Taguchi method was used to perform the experiments and analyze the data to get the optimum of volume shrinkage. The results showed that melt temperature and packing pressure was significant to the volume shrinkage. When using low melt temperature and high packing pressure, the shrinkage was low and related to the thermal expansion of the material. It would be one of the parameters to the design of double injection molding.
\end{abstract}

\section{Introduction}

Plastic injection molding is one of the most popular plastic forming processes. It can produce the complex plastic parts from the mold which is designed to make a plastic part. Over the decades, the high demand of production rates is required because of the increasing industries competition. There are many special tools and manufacturing technique are developed to improve the injection molding process and to reduce the molding problems. One of them is the reducing volume shrinkage when the injection molded part starts to cool down [1].

Volume shrinkage is a high important issue in designing complex plastic part and when it is designed as an assembly part. The part quality is related to the volume shrinkage which is caused by the injection factors such as pressure and temperature during the filling phase. The PvT diagram of the material was used and analyzed in the simulation program to reduce the volume shrinkage problem. [2-4]

It is difficult to analyze and make a troubleshooting for the plastic molded part problem. The simulation program was developed to solve the complex mathematic model with the numerical method such as finite element and finite volume. It is helpful for the designers and operators such as to reduce cost, cycle time and shrinkage of the injection molding [5-6].

This research aims to apply the design of experiment (DOE) method with Taguchi model, statistical and engineering techniques for double injection molding. The objective is the optimum of volume shrinkage for injection of two types of materials, polycarbonate (PC) and acrylonitrile butadiene styrene (ABS). Modex 3D was used to simulate the plastic injection molding process to reduce the defect and trial time which allowed the design process to be faster [7]

Taguchi uses the quadratic equation to determine the loss function as the following:

$$
\mathrm{L}(\mathrm{x})=\mathrm{k}(\mathrm{x}-\mathrm{N})^{2}
$$

Where $\mathrm{L}(\mathrm{x})=$ Loss function.

$$
\mathrm{K}=\mathrm{C} / \mathrm{d}^{2} \text { Constant of proportionality, }
$$

where $\quad \mathrm{C}$ - Loss associated with sp limit. d - Deviation of specification from target.

value.

$$
\begin{aligned}
\mathrm{x} & =\text { Quality features of selected product. } \\
\mathrm{N} & =\text { Nominal value of the product. } \\
(\mathrm{x}-\mathrm{N}) & =\text { Tolerance. }
\end{aligned}
$$

\section{Material and methodology.}

The simulation process was studied with the melt temperature, mold temperature, injection pressure, packing time, cooling time, and packing pressure as the parameters of DOE. The plastic PC and ABS were manufactured by PC WANDERLITEPC-122 CHI-MEI manufacturer and ABS POLYLAC PA777B CHI-MEI manufacturer respectively which were in the database of the simulation software. Normally, simulation software has the large material and machinery database [8]. They were used to perform the simulation. The injection process was simulated by 2 steps for injected 2 plastic materials to get the plastic part as shown in Fig. 1. The first step PC was injected to fill the half of the part. Then, the second step, ABS, was injected to fill the remaining part. The mold was designed to make a part

\footnotetext{
* Corresponding author: wipoo.sr@kmitl.ac.th
} 
following the ASTM D638 specimen as shown in Fig.2 with cooling line. The most important step was to specify, select the parameters and levels [9]. The injection molding parameters with 2 levels were set and shown in Table 1 to determine the relationship between the factors that affect the process and objective of the process [10]. The Taguchi method with L8, 2^6 orthogonal array was selected to perform the experiment.
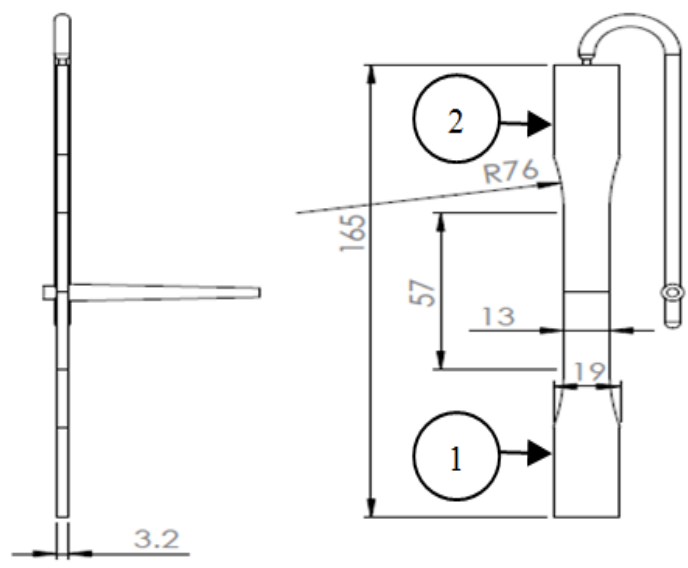

Fig 1. Part of two-material the 1 is PC plastic and the 2 is ABS Plastic

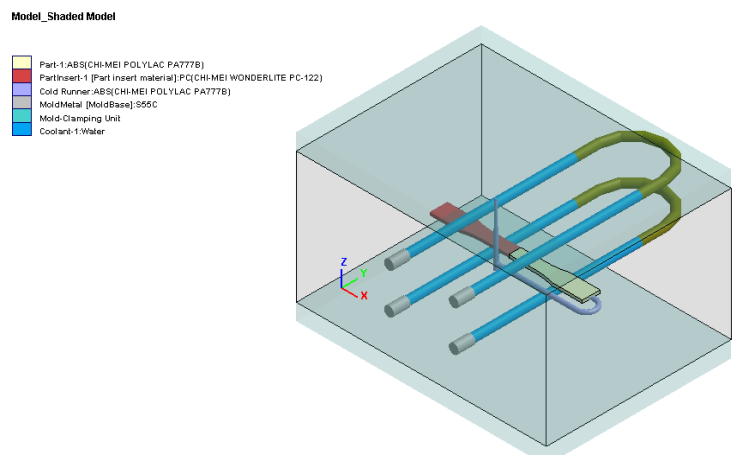

Fig 2. Standard tensile test specimen ASTM D638

Table 1. Process condition parameter in the DOE.

\begin{tabular}{|c|l|l|l|l|}
\hline No. & Control factor & Unit & Level 1 & Level 2 \\
\hline 1 & Melt temperature & $\left({ }^{\circ} \mathrm{C}\right)$ & 220 & 250 \\
\hline 2 & Mold temperature & $\left({ }^{\circ} \mathrm{C}\right)$ & 30 & 70 \\
\hline 3 & Injection pressure & $(\mathrm{Mpa})$. & 180 & 210 \\
\hline 4 & Packing time & $($ sec. $)$ & 7 & 9 \\
\hline 5 & Cooling time & (sec. $)$ & 18 & 21 \\
\hline 6 & Packing pressure & (Mpa.) & 180 & 210 \\
\hline
\end{tabular}

\section{Results and discussion}

The example of the simulation result for volume shrinkage was shown in Fig.3. The chart showed the distribution and the average of the shrinkage of the molded part. The specimen showed two different color due to different material. The experiments were performed following the Taguchi model with L8, 2^6 orthogonal array. The average volume shrinkage results for each injection molding conditions were shown in Table 2. The results showed that the smallest volume shrinkage was occurred when using the melt temperature of $250^{\circ} \mathrm{C}$, the mold temperature of $70^{\circ} \mathrm{C}$, injection pressure of $180 \mathrm{MPa}$, packing time of $7 \mathrm{sec}$., cooling time of $21 \mathrm{sec}$ and packing pressure of $210^{\circ} \mathrm{C}$. While using the melt temperature of $250^{\circ} \mathrm{C}$, the mold temperature of $30^{\circ} \mathrm{C}$, injection pressure of $210 \mathrm{MPa}$, packing time of $7 \mathrm{sec}$, cooling time of $21 \mathrm{sec}$ and packing pressure of $180^{\circ} \mathrm{C}$, the volume shrinkage was the highest.

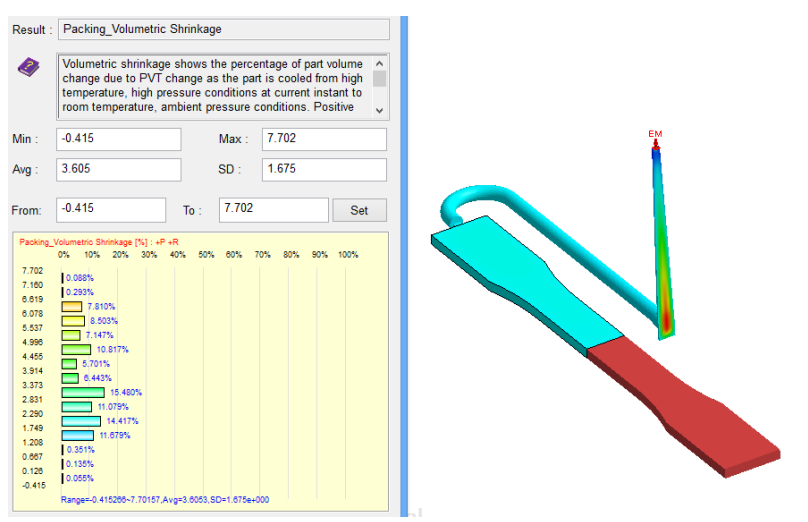

Fig 3. The volume shrinkage of the simulation result. $\square$

Table 2. The results of volume shrinkage in the simulation.

\begin{tabular}{|c|c|c|c|c|c|c|c|}
\hline No. & Tm & Tmo & Ip & Pt & Ct & Pp & $\begin{array}{c}\text { Volume } \\
\text { shrinkage }\end{array}$ \\
\hline 1 & 220 & 30 & 180 & 7 & 18 & 180 & 3.249 \\
\hline 2 & 220 & 30 & 180 & 9 & 21 & 210 & 2.986 \\
\hline 3 & 220 & 70 & 210 & 7 & 18 & 210 & 2.993 \\
\hline 4 & 220 & 70 & 210 & 9 & 21 & 180 & 3.228 \\
\hline 5 & 250 & 30 & 210 & 7 & 21 & 180 & 3.582 \\
\hline 6 & 250 & 30 & 210 & 9 & 18 & 210 & 3.574 \\
\hline 7 & 250 & 70 & 180 & 7 & 21 & 210 & 3.703 \\
\hline 8 & 250 & 70 & 180 & 9 & 18 & 180 & 3.585 \\
\hline
\end{tabular}

When considering the main effect plot as shown in Fig.4, those six injection parameters were significant for injection molded part. The molded part had less volume shrinkage when injection condition of melt temperature, injection pressure, packing time was low but mold temperature, cooling time and packing pressure was high. Moreover, melt temperature and packing pressure was effect to volume shrinkage than other factors. The less shrinkage occurred when injection molded part with low melt temperature because of less thermal expansion. While the volume shrinkage was known and defined as equation 1, the volume shrinkage was related to the temperature as shown in equation 2 . 


$$
V_{s}=\frac{V_{i}-V_{d}}{V_{d}} \times 100
$$

Where, $V_{s}=$ Volume shrinkage (\%)

$$
\begin{gathered}
V_{i}=\text { Initial test mass of solid }\left(\mathrm{cm}^{3}\right) \\
V_{d}=\text { Final volume of solid }\left(\mathrm{cm}^{3}\right) \\
a_{v}=\frac{1}{V} \frac{\mathrm{D} V}{\mathrm{D} T}
\end{gathered}
$$

Where, $a_{v}=$ Volume thermal expansion coefficient

$$
\begin{aligned}
\mathrm{V} & =\text { Area of the object }\left(\mathrm{m}^{3}\right) \\
\mathrm{D} V & =\text { Change in volume }\left(\mathrm{m}^{3}\right) \\
\mathrm{D} T & =\text { Change in temperature }(\mathrm{K})
\end{aligned}
$$

Many materials, the thermal expansion is related to the melting temperature of that material. The coefficient of thermal expansion is related to the volume changing and as well represented in the PvT diagram shown in Fig.5. The diagram also presented that using high pressure, especially packing pressure during molding, the volume shrinkage was reduced.

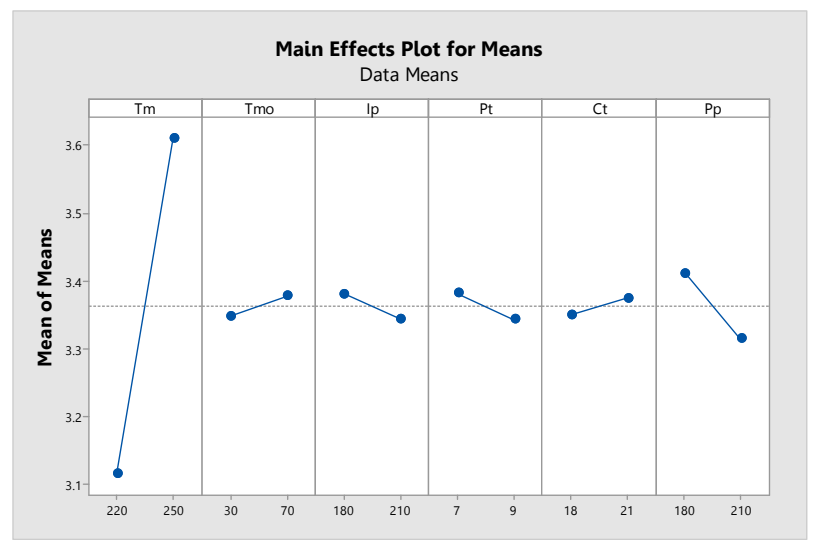

Fig 4. The relationship between injection parameter and volume shrinkage.

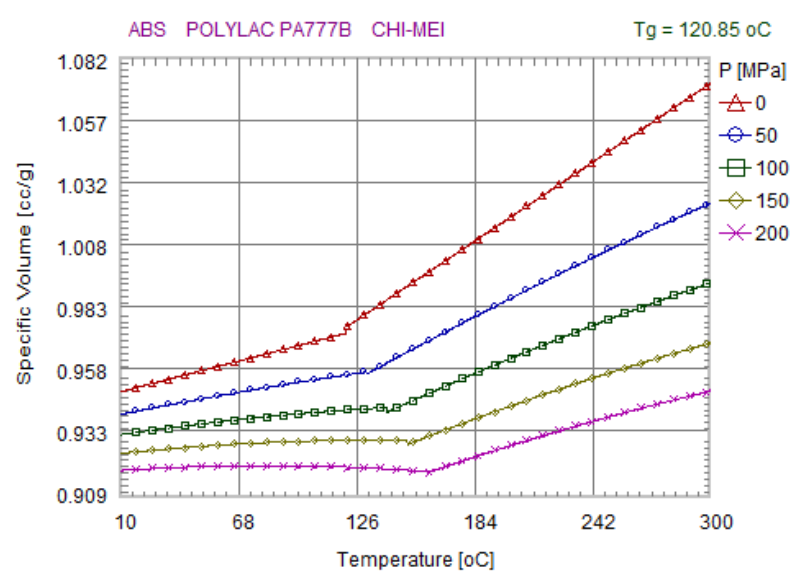

Fig 5. PvT diagram of plastic ABS POLYLAC PA777B CHI-MEI manufacturer.

Table 3. Response Table for Means.

\begin{tabular}{|c|r|r|r|r|r|r|}
\hline Level & Tm & Tmo & Ip & Pt & Ct & Pp \\
\hline 1 & 3.114 & 3.348 & 3.381 & 3.382 & 3.350 & 3.411 \\
\hline 2 & 3.611 & 3.377 & 3.344 & 3.343 & 3.375 & 3.314 \\
\hline Delta & 0.497 & 0.030 & 0.036 & 0.038 & 0.024 & 0.097 \\
\hline Rank & 1 & 5 & 4 & 3 & 6 & 2 \\
\hline
\end{tabular}

Table 3 showed an analysis to find out the effect of injection parameters to reduce volume shrinkage. Based on Taguchi method technique and data analysis by configuration $(\alpha=0.05)$. The results showed that the factor of $\mathrm{Tmo}$, Ip, Pt, and $\mathrm{Ct}$ were no significant. Opposite, $\mathrm{Tm}$ and $\mathrm{Pp}$ were significant.

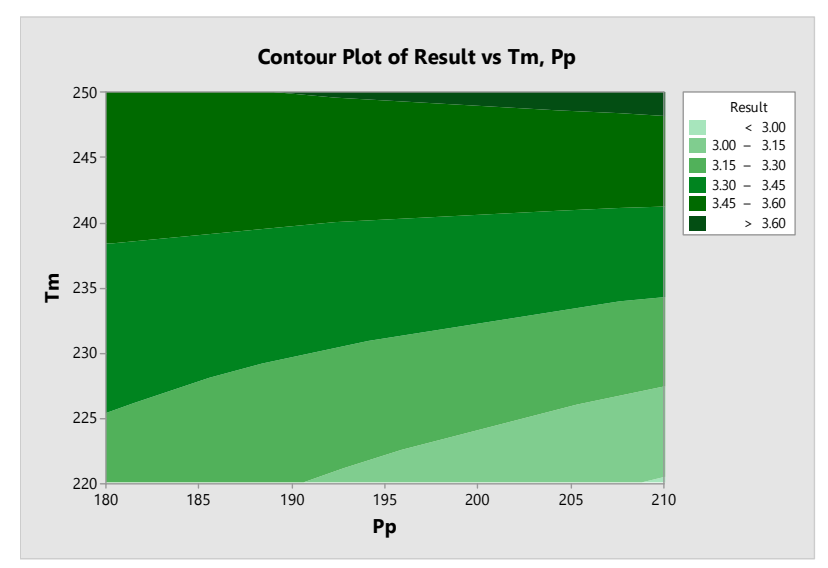

Fig 6. Contour plot of melt temperature with packing pressure.

Fig 6 showed the contour plot of melt temperature with packing pressure. The results showed that the less shrinkage occurred when using Tm of $220{ }^{\circ} \mathrm{C}$ and $\mathrm{Pp}$ of $210 \mathrm{Mpa}$. 


\section{Conclusions}

The simulation results showed that the ABS molded part had the less shrinkage when using low melt temperature and high packing pressure. The mold temperature, injection pressure, packing time and cooling time was less significant than those parameters which can be explained by the thermal expansion and PvT diagram. The results of this experiment can be the case study for double injection molding and can be applied to a commercial product such as a button air car and an automotive light bulb in the future.

\section{Acknowledgment}

The authors would like to thank the Department of Industrial Engineering, Faculty of Engineering, King Mongkut's Institute of Technology Ladkrabang, Bangkok, Thailand, and Core Tech System Co., Ltd. for supporting to access to their software simulation and research facilities.

\section{References}

1. X.Yan, J.Jianbo, Comput. Ind CD (2010)

2. S.S.Deng, C.Y.Ho,S.J.Hwang, D.Y.Hong 7682,IEEE TRANSACTIONS ON COMPONENTS (2011)

3. L.-C. Hong and S.-J. Hwang, IEEE Trans. Compon. Packag. Technol. 27, no. 2, pp. 291295, Jun. (2004)

4. Y.-S. Chang, Mech. Eng., Propulsion (2005).

5. P.K.Kennedy, Propulsion physics (EDP Sciences, TUe, (2008)

6. C.Yen, J. C.Lin, W.Li, M. F. Huang, J. Mater. Process. Technol. (2006)

7 J. G.Kovács, B. Sikló, Polym. Test.(2010).

8. Moldex3D Reference Manual R13, www.moldex 3d.com

9. C.Grolleau, C.Coutanceau, F Pierre, J. M.Leger, J. Power Sources (2010).

10. J. B.Tranter,; P.Refalo,; Rochman, A. Towards, J. Manuf. Process. (2017). 